\title{
ENTRE O CAPITALISMO E UMA PANDEMIA: reflexões introdutórias diante de uma sociedade desigual
}

BETWEEN CAPITALISM AND A PANDEMIC: introductory reflections in the face of an unequal society

Mylena Serafim da Silva*

DAVIS, M. et. al. Coronavírus e a luta de classes. Brasil: Terra sem Amos, 2020.

Indo além do que vem sendo propagado midiaticamente, discutir sobre o novo coronavírus (Sars-Cov-2) e a doença que ele provoca, a COVID-19, é também trazer à tona questões econômicas e políticas, pois as ações aplicadas para combater a pandemia rebatem diretamente nessas áreas. Diante da conjuntura provocada pela difusão da doença, é preciso analisar como essas questões estão sendo interseccionadas, além de identificar se há posicionamentos em prol da classe trabalhadora. A necessidade de isolamento e de distanciamento social mexe diretamente com o trabalho, colocando o trabalhador, especialmente aquele das camadas menos favorecidas, em situação delicada. Se por um lado é imperativo que "se fique em casa", por outro é necessário trabalhar.

Refletir, portanto sobre a desigualdade social à luz dos escritos marxianos, levando em consideração a centralidade do trabalho, e a partir deste a concepção de classes, é a fundamentação base desse livro. É nítida a crítica, não somente ao neoliberalismo - forma de governo predominante —, mas também à incógnita chinesa quanto ao seu modo de governar e a forma de enfrentar o coronavírus, é, portanto, uma reflexão fundamentada nos modos econômicos e nas formas de governo que se tornam peças-chave para as tomadas de decisão diante de tal contexto.

Sendo uma coletânea de textos escritos por seis autores reconhecidos internacionalmente no campo acadêmico, que escrevem a partir de visões de contextos diferentes - com detalhes das respectivas regiões em que vivem —, ela busca trazer apontamentos gerais e iniciais quanto à pandemia que estamos vivenciando. A edição

\footnotetext{
*Aluna do Mestrado em Sociologia (UFPB/Brasil). E-mail: mylenaserafim25@gmail.com.
} 
publicada no calor dos acontecimentos pela editora Terra sem Amos — autônoma e autointitulada "rebelde" — reúne a tradução dos seis textos e disponibiliza o arquivo digital gratuitamente, bem como o vende em formato físico por um valor simbólico e com frete grátis para todo o país.

O primeiro capítulo, A CRISE DO CORONAVÍRUS É UM MONSTRO ALIMENTADO PELO CAPITALISMO, escrito por Mike Davis, professor na Universidade da Califórnia, traz um parecer sobre a desigualdade social a partir da realidade norte-americana. Enfatizando a precariedade do sistema de saúde e a forma como o caos se repete (o vírus é familiar, bem como a situação de uma pandemia) com a falta de testes e de equipamentos de proteção individual (EPIs), por exemplo. O autor demonstra como um governo neoliberal não está preparado para esse tipo de situação, e demonstra quais são as pessoas mais prejudicadas nesse contexto.

Ao apresentar o dado de que o primeiro epicentro da doença nos EUA foi um asilo no subúrbio de Seattle, em Kirkland, contraria a ideia de que o vírus não leva em consideração a classe social. De fato, todos correm o risco independentemente da posição social que ocupam, mas há pessoas que estão mais suscetíveis devido às condições que lhes são propiciadas. Denuncia as instalações físicas desses asilos e de outros locais ditos populares que, se comparados, possuem condições ínfimas de funcionamento, o que leva até alguns trabalhadores a se recusarem a trabalhar sob tais circunstâncias.

O autor destaca as potencialidades não utilizadas da indústria farmacêutica que, em vez de produzir uma vacina universal, investe em remédios paliativos ou mesmo em outros produtos que só dizem respeito ao consumo exacerbado. Outros feitos a longo prazo, como a priorização dos serviços particulares e defasagem do sistema público (com a drástica diminuição do número de leitos hospitalares, por exemplo) também interfere diretamente na situação caótica produzida pelo vírus.

São inegáveis os avanços que esse modo de governar vem tomando — mesmo que mínimos, diz o autor - como o reconhecimento da desigualdade e a publicização disto. Entretanto Mike Davis finaliza sua escrita defendendo o enfrentamento, e apresenta como 
alternativa a atuação dos socialistas em prol de uma universalização não apenas dos serviços de saúde, mas também da economia. ${ }^{1}$

O segundo capítulo, Política ANTICAPITALISTA EM TEMPO DE COVID-19, escrito pelo geógrafo marxista David Harvey, atualmente professor de antropologia na Universidade de Nova York, deixa evidente, desde o título, o posicionamento anticapitalista e a resistência que se deve ter frente a esse modelo econômico, especialmente durante uma pandemia. Ao enfatizar a busca pelo lucro enquanto característica central desse sistema, o autor elenca algumas problemáticas que viabilizaram e facilitam a circulação do vírus, bem como pontua o enfraquecimento do capitalismo diante dessa realidade.

A partir de uma visão fundamentada no desenvolvimento geográfico, dois pontos de análise são importantes para o autor: as relações geopolíticas e as mudanças ambientais. As últimas, intituladas por ele de "segunda natureza", são responsáveis por processos decisivos como a urbanização, por exemplo. Nesse caso, o reconhecimento de que tais mudanças são frutos do capitalismo apenas reafirmam a sua culpabilidade para a composição do contexto em que estamos vivendo, conclusões já apresentadas pelo autor em outro livro (HARVEY, 2011).

É reconhecido ainda que, mesmo antes do surto da covid-19, essa forma de governo já vinha atravessando uma crise - o que não é novo - diante de protestos que vinham acontecendo mundialmente. Mas, para o autor, enfrentar uma pandemia será muito mais perigoso e ameaçador para o capital, tendo em vista o impacto direto na economia e as consequências trágicas que o vírus ainda trará para o governo em escala global, uma vez que os elos da cadeia produtiva - trabalho, produção e consumo estão prejudicados devido às medidas restritivas, com destaque para o isolamento social.

Quanto à mutação do vírus e seu poder de disseminação, David Harvey defende a ideia de que a intervenção humana no meio ambiente contribui diretamente para a pandemia. Ao comentar sobre a cultura chinesa, o autor afirma que não existe um desastre natural por si só, e que somente a partir da combinação das forças naturais com a ação humana é que pode haver tanto resultados benéficos quanto trágicos, como a propagação

\footnotetext{
${ }^{1}$ A crítica do autor vai ao encontro do que pensam Saad-Filho e Morais (2018), ou seja, o neoliberalismo nunca será uma saída para o combate à desigualdade de classes.
} 
da covid-19 pelo mundo. O que modifica é apenas a forma que o vírus chega em determinados locais devido a sua combinação com os fatores ambientais e climáticos de cada região. Todavia, devido à globalização, ele chegará mais rapidamente e atingirá toda a população, mas não na mesma proporção.

Assim como Mike Davis, David Harvey opina sobre o não investimento em produtos voltados à prevenção pela indústria farmacêutica, e reconhece que, para além da não seletividade do vírus, há desigualdades na forma de contágio, bem como no acesso ao tratamento. Para ele, a força de trabalho que está na linha de frente é sexista, racializada e etnizada e, além de estar mais exposta ao vírus, esses trabalhadores não possuem garantias trabalhistas nem condições favoráveis para continuarem trabalhando.

Mesmo eles estando premidos ao "tem que trabalhar", independente das condições externas - característica fundamental da governabilidade neoliberal, bem analisada por Foucault (2008) —, essa situação pode mudar nesse momento em que a saúde está diretamente ameaçada, não apenas individual, mas também coletivamente. E o consumo, enquanto principal forma de acumulação do capital, também se encontra drasticamente reduzido, prejudicando assim a manutenção do sistema, mas por outro lado diminuindo o impacto na degradação ambiental que há tanto tempo vem se promovendo. Desse modo, para o autor, são condições propícias para as propostas socialistas virem à tona.

O terceiro capítulo, FrançA: PEla SOCIALIZAÇÃo DO APARATO DE SAÚde, de autoria do sociólogo francês Alain Birh, é um pouco menos abrangente que os anteriores, trazendo, a partir da realidade do seu local de origem e da lógica de um comunismo libertário, a defesa de um sistema público de saúde eficaz e universal. Para comprovar que a saúde é um bem público, o autor enfatiza a tamanha importância dada pelos governos mundiais para o isolamento social, então evidenciando que o corpo para estar bem individualmente depende do meio externo - por ele nomeado "corpo social" com destaque para os serviços de saúde e de assistência social públicos e eficientes.

Diferentemente dos outros autores, para Alain Birh, a covid-19 é uma situação única, portanto não se pode tirar conclusões precipitadas. Todavia é possível apontar algumas problemáticas que já existiam, mas são atenuadas diante da pandemia, ficando evidentes até mesmo para a população. A precarização dos serviços de saúde é um exemplo enfatizado, que dentre as suas consequências está a execução do protocolo de 
ter que escolher quem irá utilizar os parcos recursos do sistema de saúde, ou melhor, quem irá sobreviver.

Situações como essa só evidenciam a irresponsabilidade do governo diante do processo saúde-doença para toda a população, com ressalvas para o setor privado que somente cresceu nos últimos anos favorecido pela lei da oferta e procura, ressalta o autor. Alain Birh reconhece que essa é uma estratégia de um governo neoliberal para priorizar a economia de mercado, e que a saúde é um bem público, por isso é preciso tomar algumas atitudes para enfrentar a situação, considerando que se trata de interesses contraditórios envolvidos. Como proposta final, considerando que saúde, "é antes de tudo, um bem público" (p. 27), o autor nos dá uma lista de propostas "que podem ser apresentadas no debate que deve acompanhar as mobilizações contra a execução de políticas neoliberais de saúde" (p. 29). Referindo-se à realidade francesa, o autor lembra que esse é o momento oportuno para se fazer "ouvir a nossa voz", chamando o governo para assumir sua responsabilidade, forçando-o a se desviar do caminho neoliberal quando passar a crise.

O quarto capítulo, CORONAVíRUS: A MILITARIZAÇÃO DAS CRISES, de autoria do teórico, político e militante uruguaio Raúl Zibechi, traz como foco a discussão sobre o controle social extremado, ou seja, a militarização. A forma como se dá o isolamento social, com destaque para as medidas chinesas, proibindo as pessoas não apenas de circular nas ruas, mas cerceando-as de todo um convívio social antes estruturado. Referindo-se a essas medidas como "quarentena" e até mesmo "confinamento", o autor destaca a normatização com que elas são recebidas pela população, e elenca algumas estratégias que são pensadas pelo Estado a partir da sua imposição, sobretudo para a classe dominada.

Por meio dessas medidas restritivas é que o medo se propaga na sociedade - em maior dimensão que o vírus, de acordo com o autor — fazendo com que as pessoas não se deem conta do quanto estão sendo reprimidas. Para enfatizar tal afirmação, Raúl Zibechi relembra outro tipo de epidemia - a gripe comum —, que mesmo causando um número significativo de mortes, o isolamento social não é recomendado, ou melhor dizendo, induzido a ser feito de forma coercitiva, por vezes até sob pena de multa ou prisão como vem ocorrendo em alguns países. 
Ao refletir sobre esta realidade que estamos vivendo, o autor pontua enfaticamente que essas medidas restritivas só beneficiam um lado: o da classe dominante. É como se o imperativo "fique em casa" (pensando no caso brasileiro) atendesse às demandas daqueles que detém o poder, mais do que, de fato, fosse uma medida estratégica para combater o coronavírus. Raúl Zibechi finaliza reconhecendo que ainda não conseguimos enfrentar tamanha militarização de crises como essa, nem enxergar como a população em massa é controlada diante de tais medidas coercitivas.

O quinto capítulo, SOBRE A SITUAÇÃO EPIDÊMICA, escrito pelo filósofo francês e professor emérito na École Normale Surpérieure de Paris Alain Badiou, inicia conscientizando o(a) leitor(a) pela repetição de uma pandemia na história, apontando três das suas características comuns, a saber: o mercado farmacêutico, a submedicalização e a não vacinação em algumas áreas. Considerando o novo coronavírus como SARS-2, o autor reconhece sua familiaridade com a Síndrome Respiratória Aguda Grave (SARS) que surgiu no início deste século, em 2003, então tratando-se de algo que se repete na história.

Dito isso, o autor problematiza a proposta do "fique em casa", argumentando que ela não pode ser seguida por aqueles que sequer possuem uma moradia. Diante de tal imperativo, por sinal causando bastante estranheza para a população como um todo, as reações são as mais diversas possíveis, que vão desde a não aceitação até as duras críticas contra o Estado. Então comparando essas atitudes com o período da "peste negra", na Idade Média, Alain Badiou problematiza a forma com que as pessoas estão lidando com a propagação do vírus.

Para analisar o contexto de uma epidemia, neste caso a da covid-19, é preciso levar em consideração e de modo transversal que as determinações do fenômeno são sociais e ambientais. Para tanto, são denunciados os pontos de origem de ambos para esse vírus. Se o natural é a relação dos seres humanos com outras espécies (na cultura chinesa o consumo de morcegos, por exemplo), o social é a posição imperial da China diante do capitalismo. A partir desse pensamento, então o autor se posiciona na defesa dessas causalidades originárias para a pandemia em curso.

A partir da política instaurada na França pelo atual presidente Emmanuel Macron, Alain Badiou dirige duras críticas ao Estado, motivadas, por exemplo, pela falta de 
investimentos nos serviços públicos de saúde. Ao anunciar que o Estado é burguês, ele esclarece como essas medidas autoritárias são excepcionais em contextos como o de uma pandemia, mas não deixam de ser estratégicas na medida em que visam, mesmo que aparentemente seja contraditório, a manutenção dos privilégios da classe dominante, tal como nos disse Wendy Brown (BROWN, 2018).

Ao corroborar com a tese de que estamos em guerra, assim como o presidente da França afirmou, Alain Badiou reconhece que tanto a economia quanto a política estão ameaçadas, juntamente com a saúde de toda a população, mas que o Estado irá priorizar a salvação do Estado (burguês) antes mesmo da saúde pública - fato que vem ocorrendo explicitamente há décadas, como nos mostram Dardot e Laval (2016). Reconhece que as consequências vão além do período de transmissão do vírus, e que o Estado precisará tomar medidas que de fato sejam efetivas. Finaliza a escrita afirmando que precisamos escolher novos políticos e acreditar na ciência e não em web notícias.

O último capítulo, UM GOLPE COMO O DE “KILL BILL” NO CAPITALISMO, escrito pelo filósofo esloveno e professor na Universidade de Ljubljana Slavoj Zizek, traz reflexões sobre a conjuntura global, viabilizando a compreensão para além do coronavírus em si. Com um discurso esperançoso, o autor compara o enfrentamento da situação pandêmica à luta corporal de Beatrix e seu inimigo no filme "Kill Bill: Volume 2" (KILL, 2004), em que ela aplica cinco golpes em cinco locais estratégicos e diferentes do corpo de Bill para explodir seu coração. Por meio dessa metáfora, o autor afirma que "a epidemia do coronavírus é uma espécie de 'técnica de cinco pontos para explorar um coração' destinada ao sistema capitalista global” (p.44). Ela é um sinal de que não podemos mais seguir o caminho que vínhamos seguido, é necessária uma mudança radical de direção.

Além dessa analogia, o autor faz críticas ao que acontece no "mundo virtual" e denuncia a problemática da disseminação de notícias falsas, bem como de posicionamentos nas redes sociais dotados de preconceitos, alegando também que o vírus é virtual. Para ele, as catástrofes, além do mal que causam, podem propiciar reflexões importantes sobre o tipo de sociedade em que vivemos. A resposta adequada para catástrofes como essa não é o pânico, mas "a ação urgente de estabelecer algum tipo de coordenação global e eficiente" (p.45). Mesmo alegando que não defende o "comunismo 
antiquado", o autor afirma que apenas uma mudança radical poderá nos salvar dessa e de outras catástrofes que ainda estão por vir.

Em conjunto, os textos refletem não apenas sobre as consequências do coronavírus para a saúde da população, mas, sobretudo, a respeito da economia global e das formas de governar, que certamente influenciam diretamente o processo saúde-doença de um modo geral. Fundamentado na teoria marxista, o livro traz uma reflexão tanto das causalidades quanto das consequências que decorrerão do momento histórico que estamos vivenciando, além de reafirmar a luta de classes existente em nossa sociedade.

Embasados, sobretudo, em uma teoria crítica da realidade social, que se opõe à forma de organização social predominante, os textos trazem a síntese das problemáticas que perpassam nossa realidade enquanto uma sociedade desigual. De um modo geral, é preciso afirmar que a reunião desses textos é essencial para a interpretação do que estamos vivenciando atualmente e, sobretudo no que diz respeito a uma visão macro, enfatizando o papel do Estado, bem como a ligação da economia e da política com a disseminação do coronavírus.

\section{Referências}

BROWN, W. Cidadania sacrificial: neoliberalismo, capital humano e políticas de austeridade. Copenhague: Zazie, 2018.

DARDOT, P.; LAVAL, C. A nova razão do mundo: ensaio sobre a sociedade neoliberal. São Paulo: Boitempo, 2016.

FOCAULT, M. Aula de 14 de março de 1979. In: FOCAULT, M. Nascimento da biopolítica: curso dado no Collége de France (1978-1979). São Paulo: Martins Fontes, 2008. p. 297-328.

HARVEY, D. O enigma do capital: e as crises do capitalismo. São Paulo: Boitempo, 2011.

KILL Bill - volume 2. Direção de Quentin Tarantino. Nova York: Miramax Films, 2004. DVD (135 min), son., color.

SAAD-FILHO, A.; MORAIS, L. Brasil: neoliberalismo versus democracia. São Paulo: Boitempo, 2018.

Recebido em: 28/04/20.

Aceito em: 14/05/20. 